\title{
Enantio- and diastereocontrol in intermolecular cyclopropanation reaction of styrene catalyzed by dirhodium(II) complexes with bulky ortho-metalated aryl phosphines
}

\author{
Francisco Estevan, Pascual Lahuerta,* Julio Lloret, Mercedes Sanaú, M. Angeles Ubeda* and \\ Jaume Vila \\ Departamento de Química Inorgánica, Facultad de Química, Universitat de Valencia, Dr. Moliner 50, \\ 46100 Burjassot, Valencia, Spain.E-mail: pascual.lahuerta@uv.es; Fax: (+34) 963544322
}

Received (in Cambridge, UK) 11th June 2004, Accepted 6th August 2004

First published as an Advance Article on the web 23rd September 2004

Enantiomerically pure dirhodium(II) complexes with orthometalated $p$-substituted aryl phosphines have been shown to be enantio- and diastereoselective in the cyclopropanation of styrene by ethyl diazoacetate. Enantioselectivities up to $91 \%$ and diastereoselectivities up to $90 \%$ are observed for ethyl cis-2-phenylcyclopropanecarboxylate

The design of new chiral catalysts to induce enantiocontrol in carbene transfer reactions is presently a subject of interest. ${ }^{1-3}$ The intermolecular cyclopropanation reaction of styrene, $\mathbf{1}$, with ethyl diazoacetate is frequently used as a model reaction to measure the stereo- and enantioselectivity of the new catalyst (Scheme 1).

Chiral copper catalysts, ${ }^{48}$ especially those with bis-oxazoline ligands, have been found to induce the highest levels of enantiocontrol. Thus, enantioselectivities up to $99 \%$ for ethyl 2-phenylcyclopropanecarboxylates have been obtained in the cyclopropanation of styrene with ethyl diazoacetate catalyzed by $\mathrm{Cu}$ catalysts. Ruthenium catalysts have also produced high level of enantiocontrol in the cyclopropanation of olefins, ${ }^{9}$ but their carbenoids are less reactive than those of copper. In general, chiral dirhodium(II) catalysts do not provide high selectivities. ${ }^{10}$ Dirhodium(II) catalysts of general formula $\mathrm{Rh}_{2}\left(\mathrm{O}_{2} \mathrm{CR}\right)_{2}(\mathrm{PC})_{2}$, containing two ortho-metalated aryl phosphines (PC) in a head to tail arrangement, ${ }^{11}$ (Figure 1), have backbone chirality and they can be isolated as pure enantiomers by conventional resolution methods. ${ }^{12}$ We have recently reported some of these dirhodium(II) catalysts as the most enantioselective among dirhodium(II) catalysts, giving enantioselectivities up to $91 \%$ and up to $87 \%$, for ethyl cis- and trans-2-phenylcyclopropanecarboxylate, respectively. ${ }^{13}$ However, these catalysts induce low diastereoselectivities, about 60:40 or lower.

According to the transition state model proposed for the cyclopropanation reaction of styrene catalysed by enantiomers of $\mathrm{Rh}_{2}\left(\mathrm{O}_{2} \mathrm{CR}\right)_{2}(\mathrm{PC})_{2},{ }^{13}$ the presence of bulky substitutents on the metalated ring might improve the diastereocontrol of the catalyst. In order to probe such hypothesis we have studied four dirhodium(II) catalysts with different substituents in the para positions of the aryl groups. These catalysts are represented in Fig. 1.

Catalysts 5 and 7 were prepared by standard methods ${ }^{14}$ from the reaction of rhodium tetraacetate and the corresponding phosphines.

$\mathrm{N}_{2} \mathrm{CHCOOEt}$

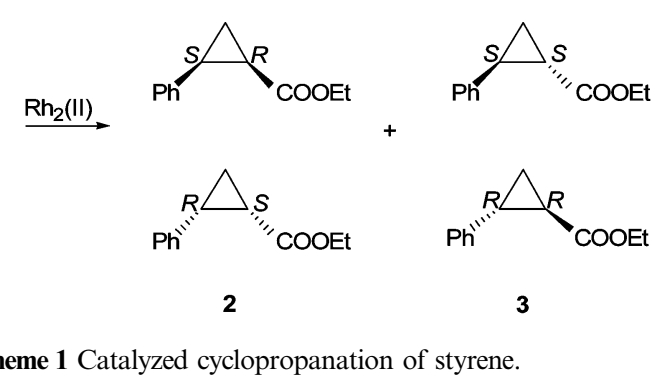

Catalyst $\mathbf{6}$ was prepared according to the method reported in the literature. $^{13}$

We now report the catalytic results obtained in the cyclopropanation of styrene with ethyl diazoacetate using catalysts 5-7 following the procedure described in ref. 13. These results are compared in Table 1 with those previously reported using catalyst 4.

As indicated in Fig. 1, all these catalysts contain different groups in the para position of all the aryl groups of the phosphine. The influence of the substituents on the diastereoselectivities of the cyclopropanation reaction is clear, increasing with the size of the substituent $\mathrm{Br}<\mathrm{Me}_{3} \mathrm{C}<\mathrm{Me}_{3} \mathrm{Si}$, with cis:trans ratios going from $53: 47$ to $90: 10$. This selectivity may be compared to the

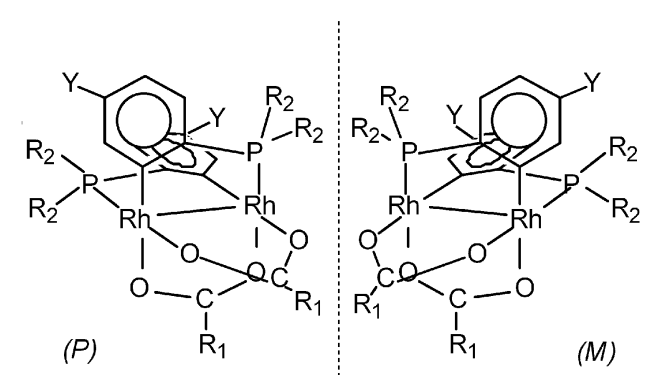

\begin{tabular}{ccccc}
\hline Catalyst & $\begin{array}{c}\text { Phosphine } \\
\mathrm{Ar}_{3} \mathrm{P}(\mathrm{Ar})\end{array}$ & $\mathrm{R}_{1}$ & $\mathrm{R}_{2}$ & $\mathrm{Y}$ \\
\hline $\mathbf{4}$ & $-\mathrm{C}_{6} \mathrm{H}_{5}$ & $\mathrm{CF}_{3}$ & $-\mathrm{C}_{6} \mathrm{H}_{5}$ & $\mathrm{H}$ \\
$\mathbf{5}$ & $p-\mathrm{BrC}_{6} \mathrm{H}_{4}$ & $\mathrm{CF}_{3}$ & $p-\mathrm{Br}_{-} \mathrm{C}_{6} \mathrm{H}_{4}$ & $\mathrm{Br}$ \\
$\mathbf{6}$ & $p-\mathrm{Me}_{3}{\mathrm{C}-\mathrm{C}_{6} \mathrm{H}_{4}}_{\mathrm{CF}_{3}}$ & $p-\mathrm{Me}_{3} \mathrm{C}-\mathrm{C}_{6} \mathrm{H}_{4}$ & $\mathrm{Me}_{3} \mathrm{C}$ \\
7 & $p-\mathrm{Me}_{3} \mathrm{Si}_{-}-\mathrm{C}_{6} \mathrm{H}_{4}$ & $\mathrm{CF}_{3}$ & $p-\mathrm{Me}_{3} \mathrm{Si}_{-}-\mathrm{C}_{6} \mathrm{H}_{4}$ & $\mathrm{Me}_{3} \mathrm{Si}$ \\
\hline
\end{tabular}

Fig. 1 Rh(II) catalysts with ortho-metalated aryl phosphine ligands used in this study.

Table 1 Asymmetric cyclopropanation of styrene catalyzed by $(M)$ enantiomers

\begin{tabular}{|c|c|c|c|c|c|c|}
\hline \multirow[b]{2}{*}{ Catalyst } & \multirow[b]{2}{*}{ Yield $\%{ }^{a}$} & \multirow[b]{2}{*}{$2 / 3^{b}$} & \multicolumn{2}{|c|}{$\%$ ee } & \multicolumn{2}{|c|}{ Configuration } \\
\hline & & & $2^{c}$ & $\mathbf{3}^{c}$ & 2 & 3 \\
\hline $4^{13}$ & 55 & $48: 52$ & 91 & 87 & $1 S, 2 R$ & $1 S, 2 S$ \\
\hline 5 & 80 & $53: 47$ & 84 & 81 & $1 S, 2 R$ & $1 S, 2 S$ \\
\hline 6 & 46 & $83: 17$ & 81 & 3 & $1 S, 2 R$ & $1 S, 2 S$ \\
\hline 7 & 39 & $90: 10$ & 91 & 7 & $1 S, 2 R$ & $1 S, 2 S$ \\
\hline
\end{tabular}

${ }^{a}$ Cyclopropanation yield based on diazoacetate. ${ }^{b}$ Determined by GC analysis and ${ }^{1} \mathrm{H}$ NMR. ${ }^{c}$ Ee values were based on GC analysis with a 2,3-di-O-acetyl-6-O-tert-butyldimethylsilyl-beta-CDX column. ${ }^{d}$ Configuration was determined by correlation of the sign of the rotation of polarized light with that of the known enantiomer. ${ }^{15}$ 


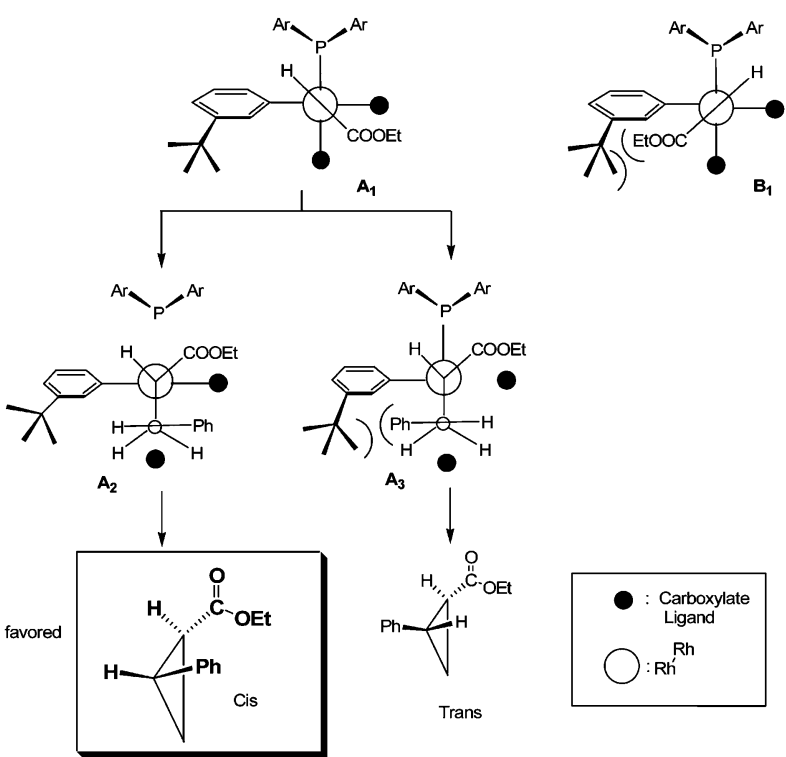

Fig. 2 Projection of coordinated carbene on $(M)$-dirhodium complex along the $\mathrm{Rh}-\mathrm{Rh}$ axis. Model for cyclopropanation of styrene.

cis:trans ratio $48: 52$ previously reported ${ }^{13}$ for catalyst $\mathbf{4}$ in which a hydrogen is attached to the para positions.

The diastereocontrol increases with the bulkyness of the catalyst and, at the same time, the enantioselectivity for the trans isomer decreases. Thus, when using catalyst 5, the enantioselectivities for $\mathbf{2}$ and 3 were almost identical ( 84 and $81 \%$ ), but the diastereoselectivity was poor, while when catalyst 7 was used the ee values were 91 and $7 \%$ and diastereoselectivity was maximised.

The observed high enantio- and diastereoselectivities for isomer $\mathbf{2}$ in the cyclopropanation of styrenes with Rh(II) catalysts $\mathbf{6}$ and $\mathbf{7}$ can be rationalised based on the model depicted in Fig. 2 for the $(M)$-catalyst. The non-metalated aryl groups of the phosphorus and also the metalated aryl group with bulky substituents limit the possible orientations of the coordinated carbene. As a result, the orientation $\mathrm{A}_{1}$ in Fig. 2, placing the ester group at the less sterically demanding quadrant in the neighbourhood of the carboxylate ligands, will be favored compared to the opposite orientation $\mathrm{B}_{1}$. The high enantiocontrol observed for these orthometalated rhodium(II) catalysts was previously been attributed ${ }^{13}$ to a discrimination between the cyclometalation pathways resulting from $\mathrm{A}_{1}$ and $\mathrm{B}_{1}$ intermediates.

With the introduction of relatively bulky substituents in the phosphines, the cyclometalation steps $\mathrm{A}_{1}$ to $\mathrm{A}_{2}$ and $\mathrm{A}_{1}$ to $\mathrm{A}_{3}$ are no longer equally favored, as in the latter, a repulsive interaction between the phenyl ring of the approaching olefin and the substituents on the metalated ring occurs at a certain moment of the process. This discrimination could explain the increasing diastereoselectivity, with the bulkiness of the phosphine substituents.

Molecular modelling studies on this system based on the molecular structure determined for $\mathrm{Rh}\left(\mathrm{O}_{2} \mathrm{CCH}_{3}\right)_{2}\left[\left(\mathrm{CH}_{3}\right)_{3^{-}}\right.$ $\left.\left.\mathrm{SiC}_{6} \mathrm{H}_{3}\right) \mathrm{P}\left(\left(\mathrm{CH}_{3}\right)_{3} \mathrm{SiC}_{6} \mathrm{H}_{4}\right]_{2}\right] \cdot 2 \mathrm{H}_{2} \mathrm{O}, 8^{16}$ the acetate analogue of catalyst 7, supports this model (Fig. 3).

In summary, results indicate that cyclometalated dirhodium(II) compounds with arylphosphines containing bulky $p$-substituents produce high diastereo- and enantioselectivities in the intermolecular cyclopropanation of styrene. The diastereoselectivities for ethyl cis-2-arylcyclopropanecarboxylate clearly exceed those

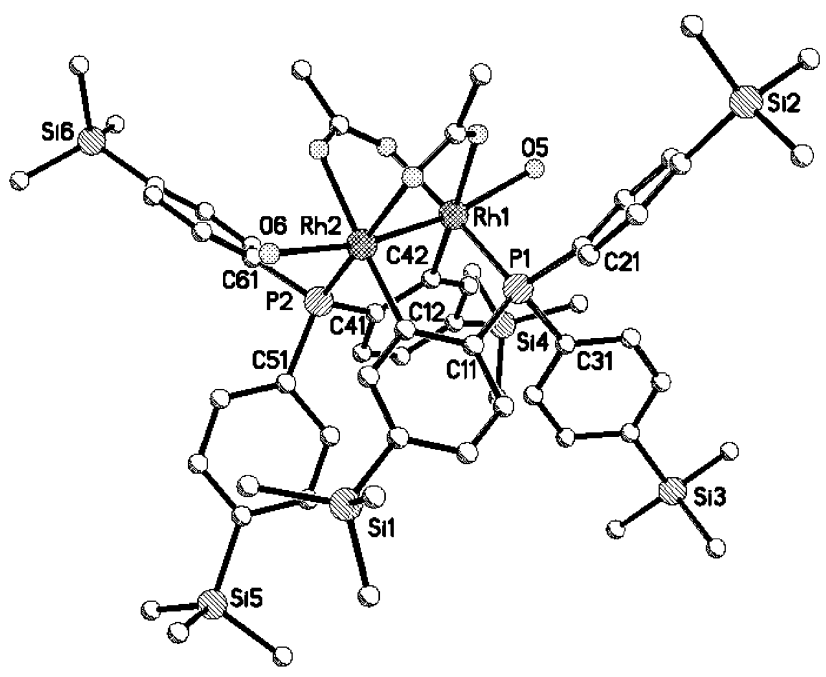

Fig. 3 Molecular diagram for $\mathbf{8}$. Hydrogen atoms are omitted for clarity. Selected bond distances $/ \AA$ are: $\mathrm{Rh} 1-\mathrm{Rh} 2=2.5116(6)$, Rh1-P1 = 2.2019(16), Rh1-C42 = 2.005(6), Rh2- P2 = 2.2078(17), Rh2-C12 = $2.004(6), \quad \mathrm{Rh} 2-\mathrm{O} 6=2.326(4)$. Selected angles $^{\circ}$ are: $\mathrm{O} 6-\mathrm{Rh} 2-$ $\mathrm{Rh} 1=170.21(12), \mathrm{C} 12-\mathrm{Rh} 2-\mathrm{Rh} 1=97.05(2), \mathrm{C} 42-\mathrm{Rh} 1-\mathrm{Rh} 2=97.42(19)$

previously observed with other Rh(II) catalysts for this particular model reaction.

We are grateful to Ministerio de Ciencia y Tecnologia (Project MAT2002-0442-1-C02-02) for financial support.

\section{Notes and references}

1 M. P. Doyle and M. N. Protopopova, Tetrahedron, 1998, 54, 7919.

2 M. P. Doyle and D. C. Forbes, Chem. Rev., 1998, 98, 911.

3 G. A. Sulikowski, K. L. Cha and M. M. Sulikowski, Tetrahedron: Asymmetry, 1998, 9, 3145.

4 T. Aratani, Y. Yoneyoshi and T. Nagase, Tetrahedron Lett., 1982, 23, 685.

5 Z. Li, Z. Zheng and H. Chen, Tetrahedron: Asymmetry, 2000, 11, 1157.

6 D. A. Evans, K. A. Woerpel, M. M. Hinman and M. M. Faul, J. Am. Chem. Soc., 1991, 113, 726

7 R. E. Lowenthal, A. Abiko and S. Masamune, Tetrahedron Lett., 1990, 31, 6005 .

8 H. Fritschi, U. Leutenegger and A. Pfaltz, Helv. Chim. Acta, 1988, 71, 1553.

9 H. Nishiyama, N. Soeda, T. Naito and Y. Motoyama, Tetrahedron: Asymmetry, 1998, 9, 2865.

10 M. P. Doyle, S. B. Davies and W. Hu, Chem. Commun., 2000, 867.

11 A. R. Chakravarty, F. A. Cotton, D. A. Tocher and J. H. Tocher, Organometallics, 1985, 4, 8.

12 D. F. Taber, S. C. Malcolm, K. Bieger, P. Lahuerta, M. Sanaú, S. E. Stiriba, J. Pérez-Prieto and M. A. Monge, J. Am. Chem. Soc., 1999, 121, 860 .

13 M. Barberis, P. Lahuerta, J. Pérez-Prieto and K. Herbst, Organometallics, 2002, 21, 1667.

14 P. Lahuerta, J. Payá, M. A. Pellinghelli and A. Tiripicchio, Inorg. Chem., 1992, 31, 1224

15 T. Aratani, Y. Nakansi and H. Nozaki, Tetrahedron, 1970, 26, 1675.

16 Crystal data: $\mathrm{C}_{58} \mathrm{H}_{82} \mathrm{O}_{8} \mathrm{P}_{2} \mathrm{Si}_{6} \mathrm{Rh}_{2}, \quad M=1343.54$, triclinic, $a=$ 15.0100(2), $b=15.8590(10), c=16.2240(2) \AA, \alpha=106.0690(6), \beta=$ $92.0150(7), \gamma=94.9480(6), V=3690.26(7) \AA^{3}, T=293 \mathrm{~K}$, space group $P \overline{1}, Z=2,16847$ reflections measured, 13141 unique $\left(R_{\text {int }}=0.0592\right)$ which were used in all calculations. The final $R_{1}$ was 0.0951 . CCDC 242554. See http://www.rsc.org/suppdata/cc/b4/b408856e/ for crystallographic data in .cif or other electronic format. 